\title{
Correlation of Cord Blood Bilirubin Values with Neonatal Jaundice in Health New-Borns: A Prospective Observational Study
}

\section{Jehangir $\mathrm{AB}^{*}$}

Kurji Holy Family Hospital, India

*Corresponding author: Jehangir Allam Bhat, Pinglena Pulwama, Kurji Holy Family Hospital, Patna, India, Tel: 7033203315; Email: ajaalam333@gmail.com

\section{Research Article}

Volume 3 Issue 4

Received Date: November 06, 2018

Published Date: December 05, 2018

\section{Abstract}

Objective: The present study was conducted to investigate the predictability of pathological jaundice on cord blood bilirubin values.

Methodology: It was a prospective observation study conducted in Kurji holy family hospital on 289 healthy new-borns. Babies were divided into two groups. Group A who developed Physiological Jaundice and Group B who developed pathological jaundice. Cord blood bilirubin was estimated in all new-born who were then followed up-to $5^{\text {th }}$ day of life. Babies who developed jaundice requiring treatment were admitted in NICU for phototherapy. Rest where checked regularly up-to $5^{\text {th }}$ day of life and value recorded on $5^{\text {th }}$ day by estimation of serum bilirubin.

Results: Incidence of pathological hyperbilirubinemia in our study was $11.2 \%$. Statistically significant correlation between cord blood bilirubin and development of pathological jaundice. Gender, age, mode of delivery and birth weight has no correlation with cord bilirubin and the subsequent development of jaundice. Cord blood bilirubin $<2.5 \mathrm{mg} / \mathrm{dl}$ when compared with subsequent development of jaundice has high specificity (83.92\%) and negative predictive value (87.35 $\%$ ). Cord blood value of $>3.5 \mathrm{mg} / \mathrm{dl}$ has high sensitivity (97.06\%), specificity (99.22\%), Positive predictive value (94.29\%) and negative predictive value (99.61\%) in predicting future development of future pathological jaundice.

Conclusion: $87.35 \%$ negative Predictive Value in the present study suggests that in Healthy Term babies (Cord Blood Bilirubin $\leq 2.5 \mathrm{mg} / \mathrm{dl}$ ) cord serum bilirubin can help to identify those new-borns who are unlikely to require further evaluation and intervention. These new-borns can be discharged with assurance to Parents. Babies with CBB level $\geq 3 \mathrm{mg} / \mathrm{dl}$ should be followed more frequently. Thus, this study concludes that cord blood total bilirubin levels reliably predict the occurrence of pathological hyperbilirubinemia.

Keywords: Cord blood serum bilirubin; Pathological Jaundice; Physiological jaundice; Phototherapy

\section{Introduction}

Hyperbilirubinemia is the most common clinical condition requiring evaluation and treatment in the new- born and a frequent reason for hospital readmission during the first week of life. Although generally a benign, postnatal, transitional phenomenon, a few neonates develop marked potentially hazardous bilirubin levels 


\section{Pediatrics \& Neonatal Biology Open Access}

that can pose a direct threat of serious brain injury [1]. Acute bilirubin encephalopathy (ABE) may ensue and evolve into kernicterus (chronic bilirubin encephalopathy), a permanent disabling neurologic condition classically characterized by (1) the movement disorders of dystonia and/or choreoathetosis, (2) hearing loss caused by auditory neuropathy spectrum disorders, and (3) oculomotor pareses ${ }^{1}$. The genesis of neonatal hyperbilirubinemia reflects the interplay of developmental red blood cell (RBC), hepatic, and gastrointestinal immaturities that result in an imbalance favoring bilirubin production over hepatic enteric bilirubin clearance.

Almost all newborn infants have a serum or plasma total bilirubin (TB) level $>1 \mathrm{mg} / \mathrm{dL}$ in contrast to normal adults in whom the normal TB level is $<1 \mathrm{mg} / \mathrm{Dl}$. Physiological jaundice usually appears on the 2nd - 3rd day, peaking between the 5th and 7th days of life. Jaundice may appear at birth or may appear any time during neonatal period depending upon the cause [2]. Since we know hyperbilirubinemia has a deleterious effect like Kernicterus, chore athetoid cerebral palsy, hearing impairment and cognitive impairment if not treated at the time. So meticulous screening of newborn is required to detect hyperbilirubinemia. Since the peak bilirubin level typically occurs at 72 to 96 hours, after healthy newborns are discharged from their birth hospital, follow-up is essential. Infants discharged before 72 hours should be seen within the next 2 days. Infants at lower gestational ages or who have other risk factors should be seen earlier [2]. This is practically impossible in underdeveloped and even in developing nations because of poverty, low education and cultural practice. Here comes the role of prediction of neonatal hyperbilirubinemia.

Early discharge of healthy term newborns after delivery has become a common practice, because of medical and social reasons and economic constrains [3]. Thus, the recognition, follow up and early treatment of jaundice has become more difficult as a result of early discharge from the hospital. Severe jaundice and even kernicterus can occur in some full term healthy newborns discharged early with no apparent early findings of haemolysis [4].

\section{Methodology}

This Prospective hospital-based study was conducted in Dept. of Paediatrics and Neonatology, Kurji Holy Family Hospital, Patna Bihar from 17 January 2016 to $30^{\text {th }}$
December.2018. A total of 289 New-born, fulfilling the predefined inclusion criteria, delivered in our hospital were studied. Proper ethical and scientific clearance was taken from concerned hospital department. Proper consent was taken from Parents of babies after explaining the risks and benefits of neonatal jaundice, phototherapy and blood sampling.

\section{Inclusion Criteria}

a. Gestational age 35weeks and above. (Based on last Menstrual period).

b. The absence of major congenital malformations.

c. Residing at Patna or nearby whose parents agree to come for follow up.

\section{Exclusion Criteria}

a. Presence of significant illness, (i.e. sepsis \& hypothyroidism).

b. Rh incompatibility

c. ABO incompatibility

d. Newborns with obvious life-threatening congenital malformation (trachea- esophageal fistula (TOF), anorectal malformation).

e. Babies with conjugated hyperbilirubinemia.

All babies delivered in KHFH were examined and a detailed antenatal and postnatal history was taken. Cases were selected if they fulfilled all the criteria set out above. Informed consent was taken from the parents and blood was collected from cord blood at birth. Blood sample of the mother was simultaneously collected and sent for Blood Grouping if it was not known from before. The cord blood sample of the infant was sent for grouping and TSB estimation and then all babies were examined by senior registrars and experts for clinical assessment of bilirubin as per Kramer's scale and by transcutaneous bilirubinometer for continuous 5 days. Babies were divided into two groups: Group A developing jaundice within physiological range and Group $\mathrm{B}$ developing jaundice which needs treatment (pathological jaundice). Babies suspected of having high bilirubin were cross checked by serum bilirubin level and admitted for treatment if needed as per AAP nomogram for hyperbilirubinemia management. Remaining babies were checked for serum bilirubin on $5^{\text {th }}$ day of life.

\section{Bilirubin Estimation}

The Serum Bilirubin was estimated by micro-bilirubin (Jendrassik \& Grof method) for that venous blood is taken 


\section{Pediatrics \& Neonatal Biology Open Access}

in four microcapillaries and centrifuged at the rate of $10000 \mathrm{rpm}$ for 5 minutes. Bilirubin estimation is done spectrophotometrically using beam method (55 nm wavelength) (micro la-300, Merck, Netherland). Calibration of bilimeter is done daily using labeteral solution.

\section{Statistical Analysis}

Data Analysis was carried out using Microsoft excel sheet. In case of Quantitative data, mean and standard deviation, as well as range (minimum \& maximum value), is computed. Sensitivity, specificity, positive and negative predictive value of different cut-points of cord blood serum bilirubin was derived. For determining the significance of each test $p$-value of $<0.05$ was used.

\section{Results}

Out of 300 new-borns enrolled, 11 could not be included in the study because of refusal of consent, drop in follow up, Rh/ABO incompatibility and admission in NICU because of cause other than hyperbilirubinemia. All new born were exclusively breast fed. A total of 289 subjects were followed up for the first five days of life with clinical assessment and laboratory investigations. Of the enrolled subjects, 169 (58.48\%) were males and 120 $(41.52 \%)$ were female with mean cord blood bilirubin and serum bilirubin during evaluation up to 5 days of $(2.6 \pm 0.8 \& 13.9 \pm 2.4)$ and $(2.5 \pm 0.4 \quad \& \quad 12.9 \pm 1.8)$ respectively with $\mathrm{P}$ value of 0.89 thus, no statistical significance (Table 1).

$208(71.179 \%)$ were babies $>37$ weeks of age and 81 $(28.03 \%)$ were $35-37$ weeks babies. Gestational age included in study has no statistically significant effect when comparison between cord blood and serum bilirubin when estimated up to $5^{\text {th }}$ day (Table 1) (P value 0.95 ) as revealed by our study in which out of total 34 babies who developed pathological jaundice meriting intervention wherein 35-37 weeks age and rest 25 where of age group $>37$ weeks with no statistical significance Similarly birth weight and mode of delivery comparison of cord blood bilirubin and serum bilirubin when estimated up to $5^{\text {th }}$ day has no statistical significance with $P$ value of 0.78 and 0.999 respectively as depicted in Table 1.

\begin{tabular}{|c|c|c|c|c|c|c|}
\hline \multicolumn{2}{|c|}{ CHARCTERISTICS } & NUMBER & $\%$ & $\begin{array}{c}\text { Cord blood bilirubin } \\
\text { Mean } \pm \text { SD }\end{array}$ & $\begin{array}{c}\text { Bilirubin during monitoring upto } \\
5^{\text {th }} \text { day of life Mean } \pm S D\end{array}$ & P Value \\
\hline \multirow{2}{*}{ GENDER } & MALE & 169 & 58.48 & $2.6 \pm 0.8$ & $13.9 \pm 2.4$ & \multirow{2}{*}{0.89} \\
\hline & FEMALE & 120 & 41.52 & $2.5 \pm 0.4$ & $12.9 \pm 1.8$ & \\
\hline \multirow[b]{2}{*}{$\begin{array}{c}\text { GESTATIONAL } \\
\text { AGE }\end{array}$} & $>37$ WEEKS & 208 & 71.2 & $2.7 \pm 0.8$ & $13.7 \pm 2.2$ & \multirow[b]{2}{*}{0.95} \\
\hline & $\begin{array}{c}35-37 \\
\text { WEEKS }\end{array}$ & 81 & 28.03 & $2.4 \pm 1.4$ & $13.2 \pm 2.2$ & \\
\hline \multirow{2}{*}{$\begin{array}{l}\text { MODE OF } \\
\text { DELIVERY }\end{array}$} & VAGINAL & 188 & 65.05 & $2.9 \pm 1.3$ & $11.9 \pm 2.0$ & \multirow{2}{*}{0.78} \\
\hline & LSCS & 101 & $34 . .94$ & $2.6 \pm 0.8$ & $12.9 \pm 2.4$ & \\
\hline \multirow{3}{*}{ BIRTH WEIGHT } & $1.5-2.5$ & 98 & 33.91 & $2.5 \pm 1.9$ & $14.21 \pm 1.4$ & \multirow{3}{*}{0.999} \\
\hline & $2.6-3.5$ & 146 & 50.52 & $2.9 \pm 1.4$ & $12.3 \pm 1.7$ & \\
\hline & $>3.5$ & 45 & 15.57 & $2.87 \pm 0.4$ & $12.5 \pm 2.8$ & \\
\hline
\end{tabular}

Table 1: Distribution of the enrolled new-born's according to gender, gestational age, birth weight and mode of delivery.

A total of 255 (84.5\%) (Group A) developed jaundice which was in physiological range so went home without any treatment. The mean $( \pm \mathrm{SD})$ serum total bilirubin in cord blood, and on day 5 of the babies in this group were
$1.6( \pm 0.4) \mathrm{mg} / \mathrm{dl}$ and $11.9( \pm 2.4) \mathrm{mg} / \mathrm{dl}$ respectively (Table 2). Statistical correlation revealed no significance with $P$ value of 0.087 .

\begin{tabular}{|c|c|c|c|c|c|}
\hline \multirow{2}{*}{ GRUOP } & \multirow{2}{*}{ NUMBER } & \multirow{2}{*}{$\%$} & Cord blood bilirubin & \multirow{2}{*}{$\begin{array}{c}\text { Bilirubin during monitoring upto } \\
5^{\text {th }} \text { day of life Mean } \pm \text { SD }\end{array}$} & \multirow{2}{*}{ P Value } \\
\hline & & & Mean \pm SD & & \\
\hline $\mathrm{A}$ & 255 & 88.2 & $1.6 \pm 0.4$ & $11.9 \pm 2.4$ & 0.087 \\
\hline $\mathrm{B}$ & 34 & 11.8 & $2.6 \pm 0.8$ & $16.7 \pm 1.8$ & 0.0001 \\
\hline
\end{tabular}

Table 2: Mean \pm SD at bilirubin levels in cord blood and $5^{\text {th }}$ day blood of neonates and their association. Group A: Physiological hyperbilirubinemia. Group B: Pathological hyperbilirubinemia 


\section{Pediatrics \& Neonatal Biology Open Access}

Total 34 (Group B) (11.76) infants developed hyperbilirubinemia up to $5^{\text {th }}$ day with cord blood bilirubin with mean bilirubin of $2.6 \mathrm{mg} / \mathrm{dl}$ with standard deviation of $0.8 \mathrm{mg} / \mathrm{dl}$ and mean serum bilirubin when estimated up to $5^{\text {th }}$ day of life of $16.7 \mathrm{mg} / \mathrm{dl}$ with standard deviation of 1.8. Statistical correlation between these two was strong with $\mathrm{p}$ Value of 0.0001 (Table 2).
Table 3 illustrates babies having cord blood bilirubin of $<2.5 \mathrm{mg} / \mathrm{dl}$ where compared with their serum bilirubin which was recorded up to their $5^{\text {th }}$ day of life Sensitivity $8.82 \%$ (CI-1.86\% to $23.68 \%$ ) and specificity of $83.92 \%$ (CI- $78.83 \%$ to $88.21 \%$ ) with Positive Predictive Value and negative predictive value of $6.82 \% \quad(2.34 \%$ to $18.26 \%$ ) and $87.35 \%$ (85.99\% to $88.59 \%$ ) respectively.

\begin{tabular}{|c|c|c|c|c|c|c|}
\hline \multirow{4}{*}{ STASTISTICS } & \multicolumn{6}{|c|}{ CORD BLOOD SERUM BILIRUBIN mg/dl } \\
\hline & \multicolumn{2}{|r|}{$<2.5$} & \multicolumn{2}{|c|}{$2.5-3$} & \multicolumn{2}{|r|}{$>3$} \\
\hline & \multirow{2}{*}{ Value } & CONFIDENCE & \multirow{2}{*}{ VALUE } & \multirow{2}{*}{$\begin{array}{l}\text { CONFIDENCE } \\
\text { INTERVAL }\end{array}$} & \multirow{2}{*}{ VALUE } & \multirow{2}{*}{$\begin{array}{l}\text { CONFIDENCE } \\
\text { INTERVAL }\end{array}$} \\
\hline & & INTERVAL & & & & \\
\hline Sensitivity & $8.82 \%$ & $1.86 \%$ to $23.68 \%$ & $66.67 \%$ & $49.03 \%$ to $81.44 \%$ & $97.06 \%$ & $84.67 \%$ to $99.93 \%$ \\
\hline Specificity & $83.92 \%$ & $78.83 \%$ to $88.21 \%$ & $92.94 \%$ & $89.07 \%$ to $95.76 \%$ & $99.22 \%$ & $97.21 \%$ to $99.91 \%$ \\
\hline Positive Likelihood Ratio & 0.55 & 0.18 to 1.68 & 9.44 & 5.72 to 15.60 & 124.24 & 31.20 to 494.69 \\
\hline Negative Likelihood Ratio & 1.09 & 0.97 to 1.22 & 0.36 & 0.23 to 0.57 & 0.03 & 0.00 to 0.20 \\
\hline Disease prevalence & $11.76 \%$ & $8.29 \%$ to $16.05 \%$ & $12.37 \%$ & $8.82 \%$ to $16.71 \%$ & $11.72 \%$ & $8.26 \%$ to $16.00 \%$ \\
\hline Positive Predictive Value & $6.82 \%$ & $2.34 \%$ to $18.26 \%$ & $57.14 \%$ & $44.67 \%$ to $68.77 \%$ & $94.29 \%$ & $80.56 \%$ to $98.50 \%$ \\
\hline Negative Predictive Value & $87.35 \%$ & $85.99 \%$ to $88.59 \%$ & $95.18 \%$ & $92.55 \%$ to $96.91 \%$ & $99.61 \%$ & $97.36 \%$ to $99.94 \%$ \\
\hline
\end{tabular}

Table 3: Statistics of values of various cord blood bilirubin levels in predicting the development of significant hyperbilirubinemia.

Neonates having cord blood bilirubin level in the range of 2.5-3 when compared with their serum bilirubin recorded up to $5^{\text {th }}$ day of life was having sensitivity, specificity Positive predictive value and negative predictive value of $66.67 \%$ (49.03\% to $81.44 \%), 92.94$ $\%(89.07 \%$ to $95.76 \%), 57.14 \%(44.67 \%$ to $68.77 \%)$, and $95.18 \%(92.55 \%$ to $96.91 \%)$ respectively. Similarly cord blood bilirubin of $>3 \mathrm{mg} / \mathrm{dl}$ has sensitivity, specificity Positive predictive value and negative predictive value of $97.06 \% \quad(84.67 \%$ to $99.93 \%), 99.22 \% \quad(97.21 \%$ to 99.91\%), $94.29 \%$ (80.56\% to $98.50 \%$ ), $99.61 \%$ (97.36\% to 99.94 ) (Table 3).

\section{Discussion}

Jaundice is a common entity which needs attention up to some days of birth. Most of the jaundice which develops in new-born is in physiological range except small fraction that need intervention like phototherapy, exchange transfusion or new modalities of treatment. Although their fraction is low usually in the range of 8-10 $\%$, as proved in our study with $11.2 \%$. But, timely diagnosis and immediate treatment is very essential because it could have devasting effect on their future life because of kernicterus, which lead to mental retardation, chore athetoid type of cerebral palsy or hearing defect. Since percentage of these side effects have dramatically decreased in last decade because of public awareness educational programs. But, still there is small fraction of new- born who fall prey to the devasting side effects of neonatal hyperbilirubinemia especially in developing country because of poor follow up, limited resources and most important parental emotional attachment, who did not want their child to get hurt even from a single needle prick. Keeping in view all these factors, the objective of this research was framed. Our study presumption was that a high serum bilirubin level at birth would also predict a high peak later in life.

Incidence of pathological hyperbilirubinemia in our study was $11.2 \mathrm{mg} / \mathrm{dl}$. This is in accordance to studies conducted by other authors like was $12.80 \%$ in a study by Awasthi S et al. [5], $12.00 \%$ as per a study by Randev S, et al. [6], $11.4 \%$ in a study by Dhanwadkar et al. [7].

In our study there was no relation between cord blood bilirubin and bilirubin monitored up to $5^{\text {th }}$ days of life when gender, gestational age, birth weight and mode of 


\section{Pediatrics \& Neonatal Biology Open Access}

delivery were compared. Similar findings were noted by Awasthi S, et al. [5] and Alpay F, et al. [8].

Incidence of pathological hyperbilirubinemia was 11.2 $\%$ in our study which is supported by research conducted by Knupfer M, et al. [9] \& Awasthi, et al. [5], who derived incidence of 10.6 and $12.8 \%$ respectively.

In our study mean cord blood bilirubin of those babies who developed pathological jaundice was $2.6 \pm 0.6$ (mean \pm SD).This finding was in accordance of the research of Bernaldo and Segre [10] investigated the predictability of umbilical cord blood unconjugated bilirubin concentration on subsequent hyperbilirubinemia and need for therapy. Utilizing a cut-off point of un-conjugated bilirubin of $2.0 \mathrm{mg} / \mathrm{dl}$, they showed that $53 \%$ babies needed phototherapy and raising the cut-off value to 2.5 $\mathrm{mg} / \mathrm{dl}$ predicted that $72 \%$ babies need phototherapy. Zakia Nahar, et al. [11] 2009 found cord blood bilirubin of
$2.5 \mathrm{mg} / \mathrm{dl} \pm 0.5$ which can predict occurrence of pathological jaundice in neonates.

Present study revealed at cord blood bilirubin level of $<2.5 \mathrm{mg} / \mathrm{dl}$, sensitivity $8.82 \%$ and specificity of $83.92 \%$ with positive predictive value and negative predictive value of $6.82 \%$ and $87.35 \%$ respectively. Thus, at cord blood $<2.5 \mathrm{mg} / \mathrm{dl}$ probability of not developing hyperbilirubinemia is $83.92 \%$. This finding was supported by Rosenfeld J, et al. [12] who found $4 \%$ incidence of NNH at cord blood bilirubin level of $<2 \mathrm{mg} / \mathrm{dl}$ with specificity of $98.23 \%$. Knupfer M, et al. [9] derived incidence of just $0.30 \%$ at serum bilirubin level of 1.17 $1.75 \mathrm{mg} / \mathrm{dl}$.

Other findings which we extracted from our study were sensitivity, specificity, positive predictive value and negative predictive value at cord blood serum bilirubin level of $2.5-3 \mathrm{mg} / \mathrm{dl}$ and $>3 \mathrm{mg} / \mathrm{dl}$ and other studies which support this are shown in Table 4.

\begin{tabular}{|c|c|c|c|c|c|c|}
\hline \multirow{2}{*}{ Studies } & $\begin{array}{c}\text { Cut off Cord STB } \\
\text { (mg/dL) }\end{array}$ & $\begin{array}{c}\text { Cut off Neonatal } \\
\text { Hyperbilirib-inemia } \\
\text { (mg/dL) }\end{array}$ & Sensitivity & Specificity & $\begin{array}{c}\text { Positive } \\
\text { Predictive Value }\end{array}$ & $\begin{array}{c}\text { Negative } \\
\text { Predictive Value }\end{array}$ \\
\cline { 2 - 6 } OUR Study & $<2.5$ & $<12$ & $8.82 \%$ & $83.92 \%$ & $6.82 \%$ & $87.35 \%$ \\
\cline { 2 - 6 } & $2.5-3$ & $14.5-15.6$ & $66.67 \%$ & $92.94 \%$ & $57.14 \%$ & $95.18 \%$ \\
\hline $\begin{array}{c}\text { Amar Taksande } \\
\text { etal }{ }^{13}(2005)\end{array}$ & $>2$ & $>16$ & $97.06 \%$ & $99.22 \%$ & $94.29 \%$ & $99.61 \%$ \\
\hline Knudsen $^{14}$ (1989) & $>2.35$ & $\geq 17$ & $89.50 \%$ & $85 \%$ & $38.80 \%$ & $98.70 \%$ \\
\hline $\begin{array}{c}\text { Zakia Naharet } \\
\text { al }^{11} \text { (2009) }\end{array}$ & $\geq 2.5$ & $\geq 15$ & $13 \%$ & $99 \%$ & $85 \%$ & $72 \%$ \\
\hline $\begin{array}{c}\text { Sun. G. et } \\
\text { al }{ }^{15} \text {.(2007) }\end{array}$ & $>2$ & $\geq 17$ & $77 \%$ & $98.60 \%$ & & $96 \%$ \\
\hline $\begin{array}{c}\text { Satrya R et } \\
\text { al }{ }^{16} \text {.(2009) }\end{array}$ & $\geq 2.54$ & $\geq 12.9$ & $90.50 \%$ & $85 \%$ & & \\
\hline
\end{tabular}

Table 4: Studies on the predictive ability of cordblood bilirubin level and the neonatal hyperbilirubinemia.

As illustrated in Table 4 our study predicts with high probability at serum bilirubin level $>3 \mathrm{mg} / \mathrm{dl}$, chances of developing pathological neonatal hyperbilirubinemia are very high. Thus, these new-born must be meticulously checked on follow up. Cord blood bilirubin level of 2.5-3.5 also showed good specificity but due to decreased sensitivity, these new born can be categorised into intermediate risk. So our study can classify new-born into three risk categorise as per cord blood serum bilirubin (Table 5).

\begin{tabular}{|c|c|}
\hline Cord blood bilirubin $(\mathbf{m g} / \mathbf{d l})$ & Risk category \\
\hline$<2.5$ & Low \\
\hline $2.5-3$ & Intermediate \\
\hline$>3 \mathrm{mg} / \mathrm{dl}$ & High risk \\
\hline
\end{tabular}

Table 5: Three risks categorise as per cord blood serum bilirubin. 


\section{Pediatrics \& Neonatal Biology Open Access}

\section{Conclusion}

The study concludes with result that there is significant correlation between cord blood serum bilirubin and development of neonatal jaundice. Cord blood bilirubin can be used to categorise neonates into risk group. Neonates with serum bilirubin $<2 \mathrm{mg} / \mathrm{dl}$ have low risk for neonatal hyperbilirubinemia, thus can be kept in low priority as compared to neonates with cord blood serum bilirubin $>3 \mathrm{mg} / \mathrm{dl}$. Neonates with Cord Blood Bilirubin level $\geq 3 \mathrm{mg} / \mathrm{dl}$ should be followed more frequently to reduce morbidity and mortality due to neonatal hyperbilirubinemia [13-16].

\section{Acknowledgement}

We are highly thankful to our paediatric department and its faculty who devoted their precious time to guide us while conducting this research. We are highly thankful to those little angels and their parents without them this research was impossible.

\section{References}

1. Watchko JF, Tiribelli C (2013) Bilirubin-induced neurological damage: mechanisms and management approaches. N Engl J Med 369(21): 2021-2030.

2. Cloherty JP, Gregory MP, Martin CR (2011) Neonatal hyperbilirubinemia. Manual of Neonatal Care 7th (Edn.), pp: 336-337.

3. Maisels MJ, Newman TB (1995) Kernicterus in otherwise healthy, breast-fed term newborns. Pediatrics 96(4): 730-733.

4. Norr KF, Naocin K (1987) Outcomes of postpartum early discharge, 1960-1986; a comparative review. Birth 14(3): 135-141.

5. Awasthi S, Rehman H (1998) Early prediction of neonatal hyperbilirubinemia. Indian J Pediatr; 65(1): 131-39.

6. Randew S, Grower N (2010) Predicting Neonatal hyperbilirubinemia using first day serum bilirubin levels. Indian J Pediatr 77(2): 147-150.

7. Dhanwadkar SS, Christo S (2016) Rasalam, Masoodet Z. Effectiveness of early clinical assessment and bilirubin estimation for prediction of neonatal hyperbilirubinemia. Int J Contemp Pediatr 3(2): 477484.

8. Alpay F, Sarici SU, Tosuncuk HD, Serdar MA, Inanc N, et al. (2000) The value of first-day bilirubin measurement in predicting the development of significant hyperbilirubinaemia in healthy term newborns. Pediatrics 106(2): 16-21.

9. Knupfer M, Pulzer F, Gebauer C, Robel-Tillig E, Vogtmann C (2005) Predictive value of umbilical cord blood bilirubin for postnatal hyperbilirubinaemia. Acta Paediatr 94(5): 581-587.

10. Bernaldo AJN, Segre CA, de Mattos (2004) Bilirubin dosage in cord blood: could it predict neonatal hyperbilirubinaemia? Sao Paulo Med J 122(3): 99103.

11. Nahar Z, Shahidukkah MD, Mannan A, Dey SK, Mitra $\mathrm{U}$, et al. (2009) The value of umbilical cord blood bilirubin measurement in predicting the development of significant hyperbilirubinemia in healthy Newborn. Bangladesh J Child Health 33(2): 50-54.

12. Rosenfeld J (1986) Umbilical cord billirubin levels as predictor of subsequent hyperbilirubinemia. J Fam Pract 23(6): 556-558.

13. Taksande A, Vilhekar K, Jain M, Zade P, Atkari S, et al. (2005) Prediction of the development of neonatal hyperbilirubinemia by increased umbilical cord blood bilirubin. Ind Medica 9(1): 5-9.

14. Knudsen A (1989) Prediction of the development of neonatal jaundice by increased umbilical cord blood bilirubin. Acta pediatr Scand 78(2): 217-221.

15. Sun G, Wang YL, Liang JF, Du LZ (2007) Predictive value of umbilical cord blood bilirubin level for subsequent neonatal jaundice. Zhonghua Er Ke za Zhi 45(11): 848-852.

16. Satrya R, Effendi SH, Gurnida DA (2009) Correlation between cord blood bilirubin level and incidence of hyperbilirubinemia in term newborns. Paediatrica Indonesiana 49(6): 349-354. 